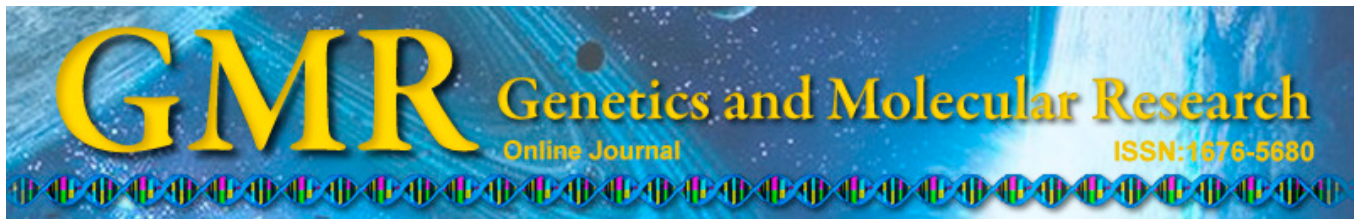

\title{
Activity of matrix metalloproteinases 2 and 9 in cultured rabbit corneal epithelium cells stimulated by tumor necrosis factor alpha
}

\author{
Z.-Q. Wu ${ }^{1,2 *}$, Z.-L. Zhang ${ }^{3 *}$, S.-W. Nie ${ }^{2}$, J. Yuan ${ }^{1}$ and Y.-N. Yang ${ }^{1}$ \\ ${ }^{1}$ Department of Ophthalmology, Renmin Hospital of Wuhan University, \\ Wuhan, Hubei, China \\ ${ }^{2}$ Department of Ophthalmology, Jinzhou Central Hospital, Jinzhou, \\ Hubei, China \\ ${ }^{3}$ Department of Gastrointestinal Surgery, Jinzhou Central Hospital, \\ Jinzhou, Hubei, China \\ *These authors contributed equally to this study. \\ Corresponding author: Y.-N. Yang \\ E-mail: 417955104@qq.com
}

Genet. Mol. Res. 14 (2): 6360-6368 (2015)

Received October 28, 2014

Accepted February 10, 2015

Published June 11, 2015

DOI http://dx.doi.org/10.4238/2015.June.11.11

\begin{abstract}
We studied the activity of matrix metalloproteinases (MMP) 2 and 9 generated by cultured rabbit corneal epithelium cells that had been stimulated with tumor necrosis factor alpha (TNF- $\alpha$ ), to investigate the possible regulative mechanisms of MMP-2/9 and their potential effect on corneal inflammatory diseases. The rabbit corneal epithelium cells were cultured in vitro and incubated with different concentrations of TNF- $\alpha(0,1,10$, and $100 \mathrm{ng} / \mathrm{mL})$ for $24 \mathrm{~h}$. The activity of MMP-2/9 was examined using gelatin zymography. The results were analyzed by computer image analysis and statistical tests. TNF- $\alpha$ stimulated the secretion of MMP-2/9 in a dose-dependent manner, and MMP-2 was activated by TNF- $\alpha$. Inflammatory factors such as TNF- $\alpha$ can stimulate MMP-2/9 activity in corneal epithelium cells. This may be a potential manipulating mechanism of MMP expression in the
\end{abstract}


pathogenesis of corneal diseases, and could play an important role in the prevention and treatment of corneal inflammatory diseases.

Key words: Corneal epithelium cells; Matrix metalloproteinases-2/9; Gelatin zymography; Tumor necrosis factor alpha

\section{INTRODUCTION}

Matrix metalloproteinases (MMPs) are zinc-dependent peptidases that play a major role in the physiological processes associated with tissue remodeling and in the pathological process characterized by excessive damage to the extracellular matrix (ECM) (Sivak and Fini, 2002). MMP-2 and MMP-9 (gelatinases A and B) are two of the most important matrix-degrading enzymes in corneal tissue. Numerous studies and our preliminary experimental results have shown that MMP-2 and MMP-9 are involved in corneal disruption, ulceration, corneal neovascularization, and other pathological processes such as corneal scar repair (Zhang et al., 2002; Yang et al., 2003a,b, 2004, 2006). Inflammatory cytokines also play an important role in corneal lesions. For example, tumor necrosis factor alpha (TNF- $\alpha$ ) is secreted by the inflammatory cells in corneal lesions for regulation of inflammatory pathways involved in cornea regeneration (Matsumoto et al., 2005).

Gene transcription and subsequent protein synthesis of MMPs are regulated by a number of factors, of which the most important are the cytokines. The purpose of this study was to observe the regulatory function of TNF- $\alpha$ in the expression of MMP-2 and MMP-9 in corneal epithelial cells. Cultured corneal rabbit cells were stimulated in vitro by the application of different concentrations of TNF- $\alpha$, and gelatin zymography was used to observe the activity changes of MMP-2 and MMP-9 in these cells. The results support a role of TNF- $\alpha$ in regulating MMP-2 and MMP-9 in corneal disease, especially in keratitis, and the suggestion of novel therapeutic TNF- $\alpha$-based methods for treatment of inflammatory corneal diseases.

\section{MATERIAL AND METHODS}

\section{Reagents and apparatus}

Dulbecco's modified Eagle medium: Nutrient Mixture F-12 (DMEM/F12) (1:1) was purchased from HyClone (Logan, Utah, USA). Fetal bovine serum was obtained from Sijiqing (Hangzhou, China). Gelatin, acrylamide, N,N'-methylenebisacrylamide, glycine, sodium dodecyl sulfate, Triton ${ }^{\mathrm{TM}} \mathrm{X}-100$, ethylenediaminetetraacetic acid, Coomassie Brilliant Blue R-250, and sodium azide were from AMRESCO (Solon, OH, USA). Pre-stained protein markers were purchased from Fermentas Co. (Beijing, China). Other reagents were all manufactured domestically to analytical purity. Vertical electrophoresis tanks and the gel imaging apparatus were from Bio-Rad (Hercules, CA, USA).

\section{Ethics}

Ethical approval was given by the medical Ethics Committee of the Renmin Hospital of Wuhan University. 


\section{Methods}

\section{In vitro culture of rabbit corneal epithelial cells}

Healthy New Zealand White rabbits were sacrificed by air embolism. The eyeballs were immediately dissected and rinsed three times in DMEM solution containing $50 \mu \mathrm{g} / \mathrm{mL}$ gentamicin and $1.25 \mu \mathrm{g} / \mathrm{mL}$ amphotericin. The corneal epithelial layer was surgically removed under a dissection microscope, placed on a Petri dish containing small amounts of culture medium, and cut into approximately $1 \times 1-\mathrm{mm}$ pieces. The tissue was then placed in $25-\mathrm{cm}^{2}$ tissue culture bottles with the epithelium face down. Each bottle contained 6 to 8 tissue blocks. The tissue culture bottles were placed in a cell incubator without medium for 15-20 min, before adding $4 \mathrm{~mL}$ cell culture medium and incubating at $37^{\circ} \mathrm{C}$ in $5 \% \mathrm{CO}_{2}$ for $48 \mathrm{~h}$. The cells were observed daily using an inverted microscope, and the culture medium was changed accordingly (every 2-3 days). After approximately 10 days, the tissue blocks were removed.

\section{Treatment of cells with TNF- $\alpha$}

When the cells reached $80 \%$ confluence (after approximately 2 weeks), the culture medium was replaced with serum-free medium for $24 \mathrm{~h}$, and then $2 \mathrm{~mL}$ aliquots of TNF- $\alpha$ of different concentrations $(0,1,10$, and $100 \mathrm{ng} / \mathrm{mL})$ were used to supplement the serum-free culture medium. The control group was supplemented with an equivalent amount of serumfree culture without TNF- $\alpha$. The cells were cultured at $37^{\circ} \mathrm{C}$ in $5 \% \mathrm{CO}_{2}$ for another $24 \mathrm{~h}$, then the culture media were collected and MMP-2 and MMP-9 activities were tested using gelatin zymography. Each sample from the different TNF- $\alpha$ concentrations was tested five times.

\section{Gelatin zymography}

The collected culture media were centrifuged for $10 \mathrm{~min}\left(1180 \mathrm{~g}\right.$ at $\left.4^{\circ} \mathrm{C}\right)$. The supernatant was isolated and, after measurement of protein concentration, was aliquoted into smaller tubes and stored at $-70^{\circ} \mathrm{C}$. A $5-\mu \mathrm{g}$ protein sample was added directly on a $10 \%$ sodium dodecyl sulfate-polyacrylamide electrophoresis gel containing $1 \mathrm{mg} / \mathrm{mL}$ gelatin without heating, and electrophoresis was conducted at $100 \mathrm{~V}$ for $2-3 \mathrm{~h}$ at $4^{\circ} \mathrm{C}$ until the bromophenol blue dye approached the gel boundary. The resolving gel containing gelatin substrate was put in a $2.5 \%$ Triton $^{\mathrm{TM}} \mathrm{X}-100$ solution and shaken for 30 min at room temperature. This process was repeated twice to remove the remaining sodium dodecyl sulfate. The gel was incubated on a shaker for $20 \mathrm{~h}$ at $37^{\circ} \mathrm{C}$ in $50 \mathrm{mM}$ Tris- $\mathrm{HCl}, \mathrm{pH} 7.5,5 \mathrm{mM} \mathrm{CaCl}_{2}$, and $0.01 \% \mathrm{NaN}_{3}$. After $1 \mathrm{~h}$ of staining with $0.5 \%$ Coomassie Brilliant Blue and destaining with $30 \%$ methanol and $10 \%$ glacial acetic acid, the MMP translucent bands in the gel detected by the image analysis system were noted, and the density and area of each band was calculated. Enzyme activities were represented as the product of the density and the area.

\section{Statistical analysis}

The SPSS 13.0 software was used for the statistical analysis. All data are reported as means \pm standard deviation. In different TNF- $\alpha$ concentration groups, the activities of MMP2, MMP-9, and the control group were compared using analysis of variance, and the Student- 
Newman-Keuls method was used to compare pairs of groups, with $\mathrm{P}<0.05$ as the statistically significant cut-off.

\section{RESULTS}

\section{In vitro culture of rabbit corneal epithelial cells}

After $48 \mathrm{~h}$ of culture, a large number of cells were observed growing outward from the tissue edge. These cells showed membrane-like extensions. Cell growth peaked around day 7 . The cells formed a monolayer with cells of a similar size. These cells were polygonal or circular and arranged in a mosaic fashion. Abundant cytoplasm and a rounded nucleus were observed in cells next to the central area, and they had typical corneal epithelial cell morphology, as shown in Figure 1.

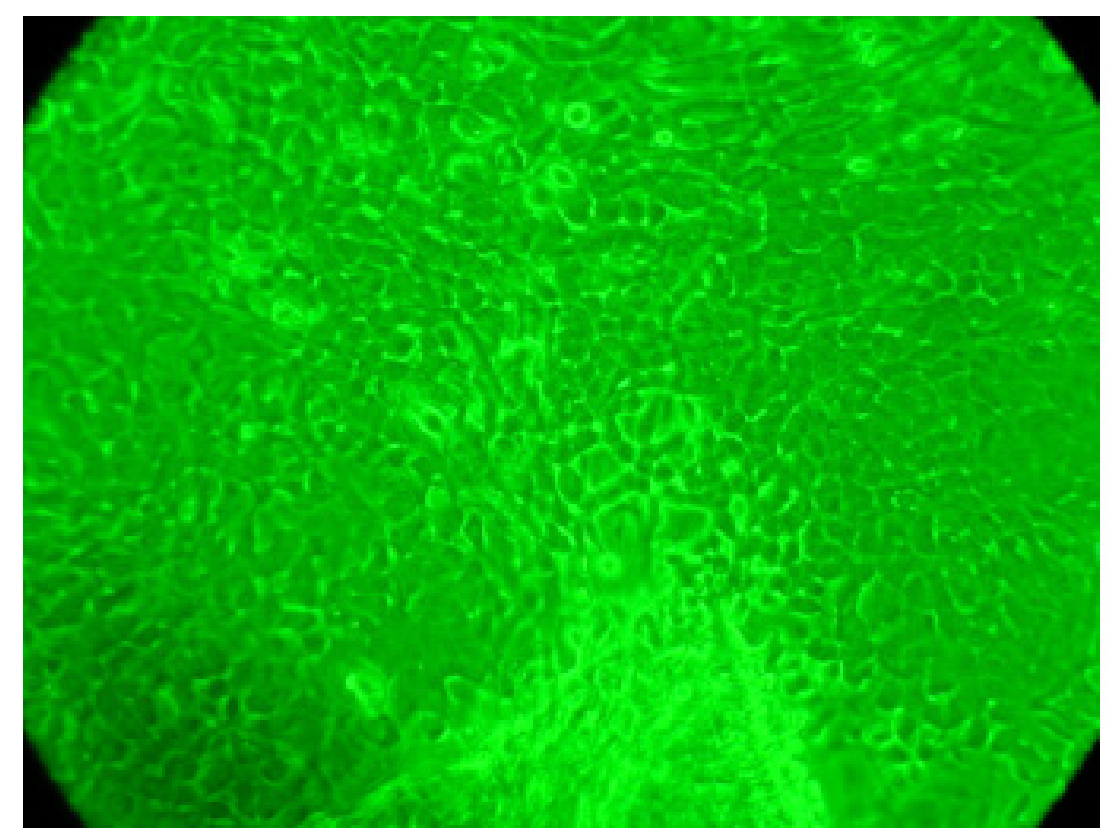

Figure 1. Cells after $48 \mathrm{~h}$ culture (100X magnification). A great quantity of rabbit corneal epithelium cells crept from the tissue and grew quickly, with approximately uniform shape and size.

\section{Effect of TNF- $\alpha$ concentration on the growth and morphology of rabbit corneal epithelial cells}

Twenty-four hours after adding TNF- $\alpha$, there were visible changes in the morphology of the rabbit corneal epithelial cells. Their size increased, the cytoplasm loosened, the cell form became irregular, and some cells were floating. As the TNF- $\alpha$ concentration increased, this change became more dramatic (Figure 2). This indicates that TNF- $\alpha$ imparts a degree of cell toxicity that results in rabbit corneal epithelial cell damage, as shown in Figure 2. 


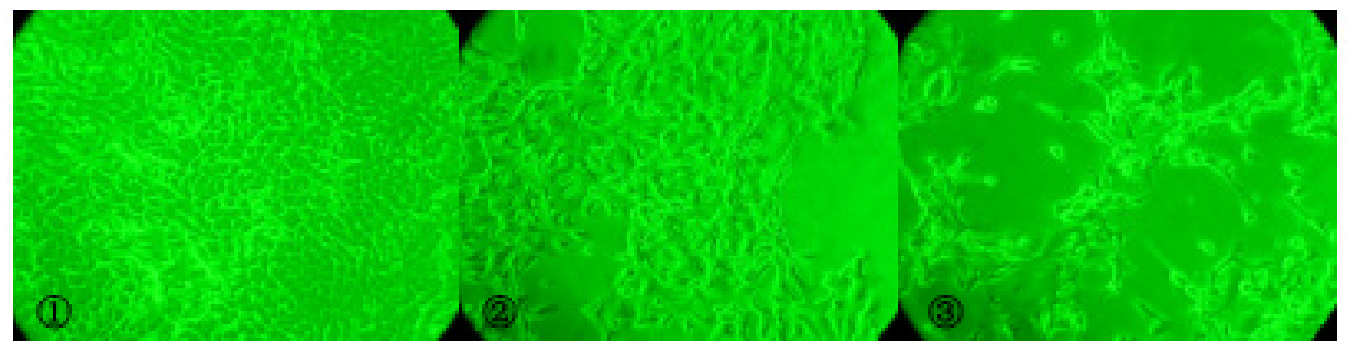

Figure 2. Sub-confluent cultures (after approximately 14 days). The cells were washed three times with cool phosphate-buffered saline and switched to serum-free medium (the same medium as used earlier but without fetal bovine serum) for $24 \mathrm{~h}$ before treatment. The cells were collected and incubated with different concentrations of tumor necrosis factor alpha (TNF- $\alpha)(0,1,10,100 \mathrm{ng} / \mathrm{mL})$ for $24 \mathrm{~h}$. (1) Control group: the cells grew in a monolayer with approximately uniform shape and size. (2) The $1-\mathrm{ng} / \mathrm{mL}$ TNF- $\alpha$ group: the appearance of the cells changed and some of the cells were floating. (3) The 100-ng/mL TNF- $\alpha$ group: the majority of cells were floating.

\section{Effect of different TNF- $\alpha$ concentrations on the activities of MMP-2 and MMP-9}

The gelatin zymography results indicate that $72-$ and $92-\mathrm{kDa}$ proteins were present in the rabbit cornea epithelium cells cultured in media without TNF- $\alpha$. This suggests that MMP2 and MMP-9 were present in the form of zymogens, and no active forms were detected. After $24 \mathrm{~h}$ induction with different concentrations of TNF- $\alpha$, the size and density of the areas of protein degradation were significantly increased. When compared with the control group, MMP activities at some TNF- $\alpha$ concentrations were statistically significant $(\mathrm{P}<0.01)$. MMP2 and MMP-9 activities between 1 and $10 \mathrm{ng} / \mathrm{mL}$ TNF- $\alpha$ were not significant $(\mathrm{P}=0.187$ and $\mathrm{P}=0.767$, respectively). However, the MMP-2 and MMP-9 activities in the $100 \mathrm{ng} / \mathrm{mL}$ group compared with the previous two groups were significant $(\mathrm{P}<0.05)$; MMP-2 and MMP-9 activities increased by 3.16 and 3.69 times, respectively, compared with the controls. This indicates that the increase in MMP-2 and MMP-9 activities by the stimulation of TNF- $\alpha$ is dose-dependent. As shown in Table 1, the integrated optical density of the bands showed that protein synthesis of MMP-2 and MMP-9 was also increased. Furthermore, after TNF- $\alpha$ induction, a $62-\mathrm{kDa}$ degradation band was observed, which represents the active form of MMP-2 (see Table 1 and Figure 3).

Table 1. Effect of tumor necrosis factor alpha (TNF- $\alpha)$ on the activity of matrix metalloproteinases 2 and 9 (MMP-2/9) in cultured rabbit corneal epithelium cells (means $\pm \mathrm{SD}$ ).

\begin{tabular}{lccc}
\hline Group & N & MMP-2 & MMP-9 \\
\hline Normal group & 5 & $75.660 \pm 8.664$ & $25.822 \pm 2.438$ \\
1-ng/mL TNF- $\alpha$ group & 5 & $214.258 \pm 7.947$ & $75.040 \pm 6.342$ \\
10 -ng/mL TNF- $\alpha$ group & 5 & $216.060 \pm 11.590$ & $80.574 \pm 8.613$ \\
100 -ng/mL TNF- $\alpha$ group & 5 & $239.176 \pm 9.285$ & $95.286 \pm 6.405$ \\
F-value & & 127.778 & 27.117 \\
P value & & $<0.01$ & $<0.01$ \\
\hline
\end{tabular}




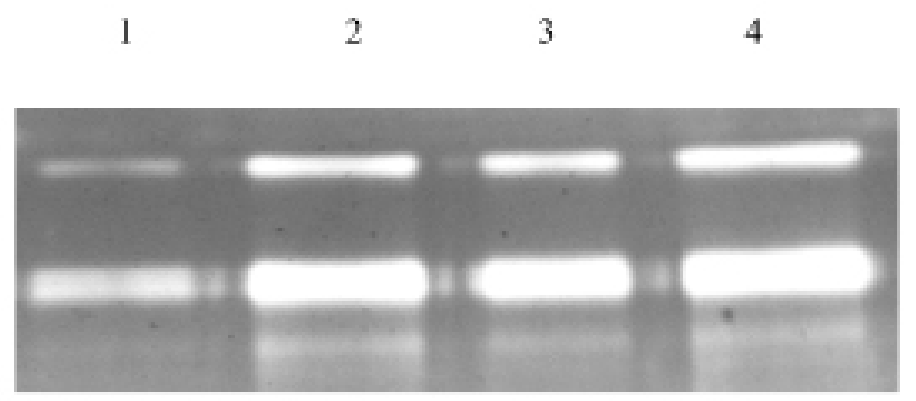

\section{-92 kDa proMMP-9}

$-72 \mathrm{kDa}$ proMMP-2

$-62 \mathrm{kDa}$ activeMMP-2

Figure 3. Effect of different concentrations of tumor necrosis factor alpha (TNF- $\alpha$ ) on the activities of matrix metalloproteinases 2 and 9 (MMP-2/9) in cultured rabbit corneal epithelium cells. Lane $1=$ Control group. Lane 2 $=1-\mathrm{ng} / \mathrm{mL} \mathrm{TNF}-\alpha$ test group. Lane $3=10-\mathrm{ng} / \mathrm{mL} \mathrm{TNF}-\alpha$ test group. Lane $4=100-\mathrm{ng} / \mathrm{mL} \mathrm{TNF}-\alpha$ test group. TNF- $\alpha$ stimulated the secretion and activity of MMP-2/9 in cultured rabbit corneal epithelium cells in a dose-dependent manner. MMP-2 was activated by TNF- $\alpha$.

\section{DISCUSSION}

During the progression of many inflammatory diseases, the decomposition and precipitation of the ECM is accompanied by the release of proteolytic enzymes, of which MMPs are amongst the most important. They are the only proteolytic enzymes that are capable of degrading all collagen fibers. MMPs are mainly secreted in the form of latent enzymes, or zymogens, that can be activated under certain conditions. This activation process is accompanied by an approximately $10 \mathrm{kDa}$ reduction in MMP molecular weight. Every MMP can degrade one or more type of ECM component and can be inhibited by the naturally occurring tissue inhibitor of metalloproteinases (TIMPs) (Wong et al., 2002). The stroma of the cornea forms $90 \%$ of the total corneal thickness. It is composed mainly of the ECM and collagen fibers. Therefore, the regulation of the MMP/TIMP system in collagen metabolism plays an important role in corneal diseases.

MMPs can be synthesized and secreted by a variety of cells, including corneal epithelial cells. At present, eight different types of MMPs have been detected in corneal tissue, namely MMP-1, -2, -3, -7, -9, -10, -13, and -14 (Wong et al., 2002). In normal cornea tissue, MMPs mainly exist as trace amounts of inactive zymogens. When corneal lesions occur, inflammatory and corneal cells secrete large amounts of proteolytic enzymes, including MMPs. These enzymes increase corneal matrix degradation, causing delayed healing of the corneal epithelium, corneal disruption, ulceration, and perforation. The gelatinase MMP-2 is one of the most abundant and the most widely distributed MMP in the family. MMP-2, together with MMP-9, degrades basement membrane components such as collagen IV, and is now extensively studied in the eye tissue (Sivak and Fini, 2002). Through numerous studies of MMP-2 and MMP-9, many investigators have shown that in corneal lesions such as keratitis (Yang et al., 2003; Xue et al., 2003), corneal alkali burn (Zhang et al., 2002; Barros et al., 2007), and corneal transplant rejection (Stuart et al., 2004), the expression levels and activities of MMP-2 and MMP-9 are increased, and they are considered the main factors contributing to these pathologies.

A number of investigative methods have been employed to investigate the expression and activity of MMPs. As proteolytic enzymes, methods to discern the role of MMPs are specialized. The method used in this study combined sodium dodecyl sulfate-polyacrylamide 
gel electrophoresis separation and identification of enzymes, coupled with the detection of enzyme activity. After a series of steps, including electrophoresis separation, protein renaturation, substrate hydrolysis, staining, and destaining, MMP activity can be observed and semi-quantitatively determined by analysis of the transparent enzyme degradation bands in the gel under the deep blue background, according to their molecular weights. Based on this approach, the two forms of the enzymes, the zymogen and the active forms, can be detected and distinguished from one another (Leber and Balkwill, 1997). In an organism, cytokines and MMPs participate in ECM degradation and decomposition. The regulatory role of MMPs in ECM reconstruction is not only dependent on the induction of proteolytic enzymes but is also regulated by TIMPs. Therefore, measurement of MMP expression does not sufficiently reflect the level of ECM degradation. Thus, the application of gelatin zymography to determine the enzyme activity of MMPs is of particular importance (Leber and Balkwill, 1997).

The molecular weight of gelatinase A (MMP-2) is $72 \mathrm{kDa}$. In this study, a transparent band with molecular weight $62 \mathrm{kDa}$ appeared on the gel. The substrate specificity indicated that this band represents the active form of MMP-2. In contrast, it was not detected in normal corneal epithelial cells. This suggests that in normal corneal epithelial cells, MMP-2 may exist mainly in its inactive form. After stimulation by TNF- $\alpha$, the inhibited MMP-2 was activated. This observation is consistent with previous studies, where MMP-2 is the main protease produced by normal cells, and mainly exists in the form of a zymogen in the normal cornea. It plays the role of "monitor". When stimulated by the inflammatory response of the body, activated MMP-2 is released and catalyzes collagen degradation (Smith and Easty, 2000). Active MMP-2 not only degrades the extracellular matrix directly but also plays a key role in the proliferation and migration of the vascular endothelial angiogenesis process (El-Shabrawi et al., 2000), thus participating in corneal neovascularization.

The molecular weight of gelatinase B (MMP-9) is $92 \mathrm{kDa}$. Our results indicate that there is almost no expression of MMP-9 in normal corneal tissue and that TNF- $\alpha$ increases MMP-9 expression and activity in corneal epithelial cells. A recent study has shown that MMP-9 is one of the major contributors to corneal tissue damage (Ikema et al., 2006). Once activated, it can promote degradation of ECM components and destruction of the corneal epithelial basement and Descemet's membranes, influence corneal epithelial formation, and cause corneal perforation.

TNF- $\alpha$ is a crucial cellular inflammatory cytokine and is an important mediator of both innate and specific immunity. There is no TNF- $\alpha$ expression in normal corneal tissue. However, in various corneal diseases, pathogenic factors induce inflammatory cell infiltration in the cornea to produce TNF- $\alpha$ and other cytokines, which form a complex network involved in the immunopathological processes of the cornea. TNF- $\alpha$ has a central role in this inflammatory response. For instance, after the cornea has been subjected to severe alkali burns, TNF- $\alpha$ levels in the tissue are closely related to the severity of the inflammation of the cornea (Saika et al., 2005). In single keratitis [herpes simplex keratitis (HSK)], herpes simplex virus 1 stimulates the activation of polymorphonuclear leukocytes, which release large amounts of TNF- $\alpha$, which is considered a key component in the development of HSK (Wasmuth et al., 2003; Heiligenhaus et al., 2005). Local injection of antisense TNF- $\alpha$ oligodeoxynucleotide in corneal tissue can significantly reduce the severity of keratitis (Wasmuth et al., 2003). In this study, the observation of floating cells and the cell morphology alteration after TNF- $\alpha$ treatment indicate that the TNF- $\alpha$ produced by inflammatory processes can, to a certain degree, be detrimental to the corneal cells. 
MMPs are secreted directly outside the cell in the zymogen form. Their expression and activity are stringently regulated at various levels. Recent studies suggest that cytokines can be used as biologically active factors that have direct or indirect effects on the genetic regulatory elements of MMPs, and therefore participate in the regulation of MMP expression (Chang and Werb, 2001). Cytokines are the main regulatory factors in the synthesis of zymogens. Extensive research has been conducted on the importance of TNF- $\alpha$ and other inflammatory factors in MMP regulation. It has been verified that inflammatory cytokines regulate MMP synthesis and secretion in an in vitro cell culture system of dental pulp fibroblasts, and many other endometrial cells. Heiligenhaus et al. (2005) found that during the process of amniotic membrane transplantation in HSK treatment, TNF- $\alpha$ levels in corneal tissue decline 2 days after the operation. Concurrently, the expression levels of MMP-2 and MMP-9 are also significantly reduced. This indicates that regulation of expression of TNF- $\alpha$, MMP-2, and MMP-9 is related. The results from our study show that as TNF- $\alpha$ concentrations increase, MMP-2 and MMP-9 activity, and enhanced MMP-2 zymogen activation and function also increase. However, the mechanism by which TNF- $\alpha$ raises MMP-2 and MMP-9 activity has not yet been clarified. We propose that signal transduction studies and drug target screens to specifically block this process and intervene with the TNF- $\alpha$ regulation of MMP-2 and MMP9 expression and activation in corneal epithelial cells may effectively control the occurrence and development of corneal ulcers. This would be of great significance for the prevention and treatment of corneal diseases and warrants further investigation.

\section{Conflicts of interest}

The authors declare no conflicts of interest.

\section{REFERENCES}

Barros LF, Barros PS, Röpke CD, Silva VV, et al. (2007). Dose-dependent in vitro inhibition of rabbit corneal matrix metalloproteinases by an extract of Pothomorphe umbellata after alkali injury. Braz. J. Med. Biol. Res. 40: 11291132.

Chang C and Werb Z (2001). The many faces of metalloproteases: cell growth, invasion, angiogenesis and metastasis. Trends Cell Biol. 11: S37-S43.

El-Shabrawi YG, Christen WG and Foster SC (2000). Correlation of metalloproteinase-2 and -9 with proinflammatory cytokines interleukin-1 $\beta$, interleukin-12 and the interleukin-1 receptor antagonist in patients with chronic uveitis. Curr. Eye Res. 20: 211-214.

Heiligenhaus A, Li HF, Yang Y, Wasmuth S, et al. (2005). Transplantation of amniotic membrane in murine herpes stromal keratitis modulates matrix metalloproteiases in the cornea. Invest. Ophthalmol. Vis. Sci. 46: 4079-4085.

Ikema K, Matsumoto K, Inomata Y, Komohara Y, et al. (2006). Induction of matrix metalloproteinases (MMPs) and tissue inhibitors of MMPs correlates with outcome of acute experimental pseudomonal keratitis. Exp. Eye Res. 83: 1396-1404.

Leber TM and Balkwill FR (1997). Zymography: a single-step staining method for quantitation of proteolytic activity on substrate gels. Anal. Biochem. 249: 24-28.

Matsumoto K, Ikema K and Tanihara H (2005). Role of cytokines and chemokines in pseudomonal keratitis. Cornea 24: S43-S49.

Saika S, Miyamoto T, Yamanaka O, Kato T, et al. (2005). Therapeutic effect of topical administration of SN50, an inhibitor of nuclear factor-kappaB, in treatment of corneal alkali burns in mice. Am. J. Pathol. 166: 1393-1403.

Sivak JM and Fini ME (2002). MMPs in the eye: emerging roles for matrix metalloproteinases in ocular physiology. Prog. Retin. Eye Res. 21: 1-14.

Smith VA and Easty DL (2000). Matrix metalloproteinase 2: involvement in keratoconus. Eur. J. Ophthalmol. 10: 215226. 
Stuart PM, Pan F, Yin X, Haskova Z, et al. (2004). Effect of metalloprotease inhibitors on corneal allograft survival. Invest. Ophthalmol. Vis. Sci. 45: 1169-1173.

Wasmuth S, Bauer D, Yang Y, Steuhl KP, et al. (2003). Topical treatment with antisense oligonucleotides targeting tumor necrosis factor-alpha in herpetic stromal keratitis. Invest. Ophthalmol. Vis. Sci. 44: 5228-5234.

Wong TT, Sethi C, Daniels JT, Limb GA, et al. (2002). Matrix metalloproteinases in disease and repair processes in the anterior segment. Surv. Ophthalmol. 47: 239-256.

Xue ML, Wakefield D, Willcox MD, Lloyd AR, et al. (2003). Regulation of MMPs and TIMPs by IL-1beta during corneal ulceration and infection. Invest. Ophthalmol. Vis. Sci. 44: 2020-2025.

Yang Y, Li F, Xing Y, He T, et al. (2006). Expression of matrix metalloproteinase in herpes simplex keratitis with amniotic membrane transplantation. Chin. Ophthalmic Res. 24: 268-271.

Yang YN, Bauer D, Wasmuth S, Steuhl KP, et al. (2003a). Matrix metalloproteinases (MMP-2 and -9) and tissue inhibitors of matrix metalloproteinases (TIMP-1 and -2) during the course of experimental necrotizing herpetic keratitis. Exp. Eye Re. 77: 227-237.

Yang YN, Bauer D, Xing Y, He T, et al. (2003b). Localization of matrix metalloproteinases in experimental herpes simplex virus keratitis. Chin. Ophthalmic Res. 21: 489-492.

Yang YN, Bauer D, Li HP and Heiligenhaus A (2004). Expression of matrix metalloproteinases in experimental herpes simplex virus keratitis. Zhonghua Yan Ke Za Zhi 40: 395-399.

Zhang H, Li C and Baciu PC (2002). Expression of integrins and MMPs during alkaline-burn-induced corneal angiogenesis. Invest. Ophthalmol. Vis. Sci. 43: 955-962. 